\title{
THE ROLE OF SIGNALS IN ONLINE AUCTION PURCHASE DECISIONS
}

Jacek Cypryjański, Ph.D., Assoc. Prof.

University of Szczecin

Institute of IT in Management

Faculty of Economics and Management

Mickiewicza 64, 71-101 Szczecin, Poland

e-mail: jacek.cypryjanski@wneiz.pl

\author{
Aleksandra Grzesiuk, Ph.D., Assoc. Prof. \\ West Pomeranian Business School \\ Department of Management \\ Faculty of Economics and IT \\ Żotnierska 53, 71-210 Szczecin, Poland \\ e-mail:agrzesiuk@zpsb.pl
}

Received 2 October 2014, Accepted 29 April 2015

\begin{abstract}
There is a growing interest in behavioural economics contradicting the empirical prediction of rational choice theory once applied to online auctions. The issue is of particular relevance due to the large use of online auctions and the anticipated growth in the future. Online auctions combine the conventional auction model with information technology. However, information asymmetry within such auctions causes risks and uncertainties that influence consumer purchase intentions. The research investigates online consumers' behaviour. The Authors suggest that due to the high perceived risk of the online buying process consumers are prompted to use cues of seller' reputation. In a series of six experiments conducted via the auction site Allegro.pl in Poland a number of signals from auction web pages has been manipulated to influence purchase intention. The results suggest that several signals can be used to stimulate online customers' behaviour. The results of these experiments indicate that buyers are more susceptible to the influence of "visual" signals than signals that require greater involvement of the buyer (to read information). The conducted experiments contribute to a more comprehensive understanding of online auction users' behaviour. And finally it provides some managerial implications to increase online auction effectiveness from the seller's perspective.
\end{abstract}

Keywords: online auction, signalling theory, online auction buying process, purchase intention.

JEL Classification: M39, C93. 


\section{Introduction}

Participating in online auctions has become one of the most popular e-commerce activities in Poland. A special role in this market plays the auction platform Allegro.pl. It was the first platform in Poland and has remained the undisputed market leader with a share exceeding $80 \%$. To understand the role of online auctions in e-commerce in Poland it should be underlined that the e-commerce market generates about 3.5\% of retail sales in Poland (Internet Standard Report, 2013). This share is steadily increasing, which is associated with the dissemination uptake of the Internet and the growing confidence of Internet users to e-commerce. Over 16 million Polish internet users visit pages that offer online shopping. Among men, the most popular are online auctions, among women e-shops. Gemius analysed the traffic on the side of e-shops, online auctions and shopping tours. The data (January-March, 2014) show 12.9 million Polish users enter online stores. A similar interest is part of Internet auctions (12.8 million Internet users). In both cases, there was an increase of almost one-fifth of Internet users compared to the previous year.

The role of online auctions in the Polish e-commerce market should be analysed due to their special use by online shops. Companies operating on the Polish e-commerce market very often use the Internet channel as an additional distribution channel. Standard Internet Research shows that just over $14 \%$ of companies active in the e-commerce sector in Poland focus exclusively on the Internet channel.

As many as two-thirds of Polish e-shops offer their products on auction sites. The advantages of selling on auction are the ability to reach a large number of potential customers without the need for long-term or expensive advertising campaigns. The second, no less important factor is the ability to use a recognizable auction brand platform (strong brand recognition of Allegro) and no need of developing their own IT infrastructure and trading platform.

These significant advantages must be confronted with the weaknesses of online auctions. First of all, the massive amount of those auctions that appear each day, which in turn makes it difficult to distinguish the offer of the company and to reach the customer. Thus, for businesses involved in the auctions, it is important to recognize the possibilities of the effective display of their offer on the auction. Hence the authors' interest in online auction problems, especially taking into account the relevant aspects of the presentation of the offer during the auction. The research investigates online consumers' behaviour in terms of their sensitivity to changes in selected elements of the visual presentation of the online auction. Visual elements form the core of the signals received by a potential buyer. Therefore the aim of the paper is to investigate 
the role of selected visual signals on online auction results from the perspective of a signalling theory.

\section{Signalling theory}

In general, signalling means the transmission of information by visible, audible, or other detectable means. Since prehistoric times humans have sought and employed ever more effective means of communicating over distance. Therefore signalling is the crucial element of human communication.

Signalling theory is an important research program, truly interdisciplinary, bridging social and natural sciences with applications in: economics, biology, sociology, anthropology, psychology, political science, law, philosophy, even chemistry and other disciplines. It refers to a body of theoretical work examining communication between individuals.

On the basis of economics and management, a signalling theory emerged from the study of the economics of information, particularly in situations where different parties in a transaction have different levels of information relevant to the transaction (Spence, 1974). The theory is analysed with a marketing perspective, particularly in the context of semiotics marketing (Nanarpuzha, 2014; Oswald, 2012).

An e-business environment results in information asymmetry because buyers cannot physically evaluate the quality of products and easily assess the trustworthiness of sellers. Product and seller quality are communicated through website signals.

As Gregg and Walczak (2008) conclude, the nature of online auction markets makes them especially useful for studying purchasing behaviour where there is incomplete or asymmetric information.

Online auctions combine the conventional auction model with information technology. However, information asymmetry within such auctions causes risks and uncertainties that influence consumer purchase intentions.

In online auctions, the consumer has no direct contact with the subject of the transaction. The customer can have broad knowledge of the range or type of product but not the particular subject of the transaction. In this case, the particular product, the subject of the online transaction, is known only on the basis of information provided by the seller.

Therefore, the customer is entirely dependent on the seller for information related to the product, its quality, and its condition. This information asymmetry (Akerlof, 1970) makes it very difficult for consumers to assess product quality before making a purchase. In addition, 
online auction transactions usually occur between unknown parties (Resnick, Zeckhauser, 2002), which leads to uncertainty about the service the business will provide, as well as whether the business will actually deliver the purchased product (Gregg, Scott, 2006). Additionally, Resnick and Zeckhauser (2006) provided an experiment on an Internet reputation mechanism. They argue that a high-reputation, established online auction retailer can achieve a higher price than a new seller with no reputation.

In this setting, consumers would like information that allows them to distinguish the business that will provide high quality goods or a high level of service from the business that will provide lower quality goods or a lower level of service. In environments with incomplete information, consumers must rely on signals provided by businesses to evaluate their ability to produce (and deliver) quality products.

\section{Quality Signals and Cues}

In communication theory the term "cue" refers to all the things we perceive that indicate some other hidden state or intention and the word "signal" is reserved for those cues that are meant to serve as communication, either because they have evolved for that purpose or because they are intentionally communicative. Cues are any feature of the world, animate or inanimate, that can be used as a guide to future action (Hasson, 2000; Maynard Smith, Harper, 2003). Everything that we use to infer a hidden quality is a cue. A cue is a signal only if it is intended to provide that information.

Signals are cues that are meant to indicate some quality. More precisely, a signal is a perceivable action or structure that is intended to or has evolved to indicate an otherwise unperceivable quality about the signaller or the signaller's environment. The purpose of a signal is communication and its goal is to alter the receiver's beliefs or behaviour (Donath, 2007).

The marketing literature has brought numerous studies on quality signals and cues used by customers. However for the purpose of the presented paper the research focus is on signals and their role in business communication. The most frequently analysed signals are price (Rao, 2005), brand equity (Erdem, Swait, 1998), retailer reputation (Biswas, Biswas, 2004; Dawar, Parker, 1994), product ingredients (Richardson et al., 1994), and warranties or guarantees (Purohit, Srivastava, 2001). Researchers have shown that the most important cues are brand, then price and retailer reputation. The total effect of different cues has not been the sum of their single effects. This is because the role of particular cues (excluding brand) have been abating in a multi-cue situation (Rao, Monroe, 1989). There have been some interactions between cues as 
well. While the respondents have presented expensive tires, the products have been evaluated positively or negatively depending on additional information regarding the manufacturer's reputation (Miyazaki et al., 2005). Analogically to product evaluation, customers have used cues to evaluate unknown quality (credibility, reliability) of retailer.

This study seeks to investigate the signals on which customers may rely on during an online auction. Online retailers seek to manage customers' service expectations. However, the tangible signals of service quality that are available to brick-and-mortar retailers (such as location, store appearance, and salespersons' behaviour) may not be available in online markets.

In an online environment, important elements are any data and atmospheric cues that an operator can provide on the user's screen.

Website quality has received broad attention from research to date. The wide range of studies confirm that information content, design, security and privacy are tools used by shoppers in discriminating between low and high quality online supplier's.

San Martin and Camarero (2009) show that online buyers trust a web site based on their previous satisfaction while users who have a more perceived risk need to verify the firm's reputation and experience.

If so, the other side of a transaction (a seller) uses this knowledge for its own purposes. Information signals provided within websites are used to influence consumers' overall perceptions of value, which can be a driving factor in e-business success. These signals can include the presentation and quality of product information and background information provided about the business and its policies. It is important due to customers' perceived risks in online transactions.

Gregg and Walczak (2008) suggested that even the name can reflect on the appearance of the professionalism of the online business. Taken together, these factors create an online e-image for the business and for the particular online transaction. Successful online transactions need positive e-images created by providing the type of information and interaction necessary to satisfy website users and potential customers.

Mavlanova, Benbunan-Fich and Koufaris (2012) developed a three-dimensional framework to classify website signals on the basis of a signalling theory. They found that lowquality sellers were likely to avoid costly and easy-to-verify signals and used fewer signals than high-quality sellers did, which used costly and difficult-to-verify signals and displayed more signals.

The number and character of customers' opinions about the retailer have been likely to play the role of the cues in an online context. If the customer has not acquired other possibilities to evaluate retailer reputation (retailer quality), the number of opinions have been of great 
consequence. Wanat and Grzesiuk (2009) supported the observations that other consumers' opinions could be used as a buyer's quality cues in an online transaction.

Mitra and Fay (2012) found evidence that online retailers can use price to manage their customers' service expectations.

As the purpose of this study is concerned, the research and findings provided by Shen, Chung-Chi, Chiou, Jyh-Shen, Kuo, Biing-Shen (2011) are of great importance. They have classified signals from auction web pages into three types: seller reputation, product condition and argument quality. To understand how the signals affect consumers' online buying decisions, the mentioned study tested the impacts of these signals on the auction outcomes variables: number of bids, auction success and willingness to pay.

\section{Buyer's purchase behaviour in online auctions}

To understand online customer behaviour the nature of perceived risk in online shopping should be taken into account and studies should be focused on prevalent motivators and drives of customers once they enter an online environment.

Due to uncertainty and the impersonal nature of online transactions, perceived risk can be viewed as a critical element of the online decision-making process. The literature provides a wide range of studies on perceived risk. For the purpose of the following paper, perceived risk will be viewed as a consumer's belief about the potential uncertain negative outcomes from the online transaction (Kim et al., 2008).

Other aspects of online purchase behaviours should also be included in the analysis. As an example, online auctions have attracted emotional shoppers through exciting shopping processes such as searching and bidding (Min-Young et al., 2013).

As discussed above, online customers would look for quality signals to reduce perceived risk.

Bo-Xu, Lin and Shao (2010) show that buyer's purchase behaviour and usage of a risk relief service for a transaction in buy-it-now auctions are determined by the perceived risk, which is influenced by the buyer's risk attitude, seller online reputation, and the product price and type.

Many factors of the buying process have been discussed and empirically confirmed to have a great impact on consumers' online auction purchasing intention. The most important are: price, product information, brand, seller reputation, number of bidders and auction time (Wu et al., 2011). However Wu, Huand and Fu (2011) show that e-retailer reputation has a more 
significant influence on general risk than product price does. Therefore it can be presumed that online auction buyers will be affected by any type of signals regarding seller reputation.

Lo, Chiu and Hsieh (2013) indicate that using a photograph to introduce the product acquires a higher bidding intention and bidding amount than not using a photograph. In addition, a web page using physically attractive models in photographs acquires a higher bidding intention and bidding price than a web page using physically unattractive models in photographs.

Previous studies show that individual decision making is influenced by others (Lascu, Zinkhan, 1999). When facing a surfeit of information, people frequently imitate others rather than make decisions based on existing conditions (Bonabeau, 2004). Herd behaviour describes social situations in which individuals are strongly influenced by the decisions of others (Asch, 1956). This construct has been widely used by marketing practitioners to induce consumer purchase intentions (Lascu, Zinkhan, 1999). Herd behaviour has been identified in online consumer product attitude (Lee et al. 2008) and purchase choices (Hanson, Putler, 1996; Chen, 2008). However, herd behaviour in relation to online auctions has only recently attracted research attention.

Chen and Wang (2010), present studies that are part of a trend in contemporary research on herd behaviour. The experimental results demonstrated that bidders use online herd cues when making decisions in online auctions. Additionally, the effects of herd cues on bidder online choices were stronger in high-involvement than low-involvement participants.

Chen (2011) addressed the influence on bidder online choices of herd cues frequently found in online auctions, including bid number, feedback ratings, and number of questions and answers. This research also investigated the effect of different levels of herd cues on bidder online choices under high and low brand awareness in online auctions. The experimental results demonstrated that bidders use online herd cues when making decisions in online auctions. Additionally, different levels of herd cues influence bidder online choices in both high and low brand awareness product situations.

\section{Experimental procedure}

The experiments are concerned with assessing the impact of choices made by an online auction buyer with respect to the quality signals provided on an auction website. The aim of the experiments was to determine the effect of six selected characteristics of an online auction on sales volume. These are auctions "buy-it now price", with a certain number of units of 
a selected product. Each buyer is able to purchase any volume offered for sale for a given price. The experiments were conducted in Poland, via the auction platform Allegro.pl

Allegro.pl is the market leader on the auction platform market in Poland and the biggest Polish web service with a market share over $81 \%$. It has more than 7 million active users in Poland (akcjostat.pl). For comparison, the market share of eBay in Poland was about $1.3 \%$ in 2014. A primary contribution of this research is that it demonstrates the ability to use Allegro.pl as an experimental laboratory for testing hypotheses about Polish customers' purchasing behaviour online. By using the Allegro platform, the authors created an online transaction environment close to the real business situation. The experiment consists of a series of transactions. The basic transaction was the sale of a mobile phone pouch.

The research aims to develop and test based on the information signalling theory. It classifies signals from auction web pages into two groups: seller reputation, and argument quality/product presentation. To understand how the signals affect online consumers' buying decisions, the study intends to test the impacts of these signals on the auction outcome variables: number of bids and success of the auction, by which we mean the number of units sold.

Each experiment consisted of two parallel conducting auctions (auction A and auction B). Auction A was designed and prepared to achieve the highest possible volume of sale. Auction B differed from auction A one of the selected features. To limit the scope of our investigation, we focused on six selected variables. Selected variables were adopted as a result of brainstorming carried out in a group of experts (persons who offer for sale goods or buy at online auctions). Table 1 shows the combination of the stimuli used in this study.

Table 1. The list of variables for auction B

\begin{tabular}{|c|l|c|c|}
\hline $\begin{array}{c}\text { No. of the } \\
\text { experiment }\end{array}$ & \multicolumn{1}{|c|}{ Variable for auction B } & $\begin{array}{c}\text { Relation with } \\
\text { the number of hits } \\
\text { on the website }\end{array}$ & $\begin{array}{c}\text { Relation with } \\
\text { the online auction } \\
\text { sales volume }\end{array}$ \\
\hline 1 & $\begin{array}{l}\text { The auction has not been featured on the list of auction } \\
\text { (this is a paid service) }\end{array}$ & H 1.1. & H 1.2 \\
\hline 2 & $\begin{array}{l}\text { The lower reliability of the seller } \\
\text { (fewer online customers' comments) }\end{array}$ & H 2 \\
\hline 3 & $\begin{array}{l}\text { Less attractive form and content of the description of the } \\
\text { product }\end{array}$ & H 3 \\
\hline 4 & $\begin{array}{l}\text { The higher price of the product and lower cost of delivery } \\
\text { (total cost of purchasing the same as for the first auction) }\end{array}$ & H 4.1 & H 4.2 \\
\hline 5 & Amateur, made a mobile phone picture of the offered product & H 5.1 & H 5.2 \\
\hline 6 & Auction title was written by small letters instead of in capitals & H 6.1 & H 6.2 \\
\hline
\end{tabular}

Source: own research. 
The experiments were designed to observe the auctions, which take place simultaneously and the results of these auctions were measured by the number of hits on the website and by the number of items sold.

In total, the research framework covers a series of six experiments (Table 1), which were carried out for two different mobile phone pouches (E1, E2), each designed for a different model of mobile phone.

The experiments lasted six weeks. Every week, one experiment was carried out for the case E1 and E2 one for the case. However, the experiments for E2 were carried out in reverse order. Thus we have for each variable fourteen observations, including seven for E1 and seven for E2. Table 2 presents the total results for each experiment measured as the sum of all the results obtained for the E1 and E2 for seven days of the online auction E1 and seven days of the online auction E2.

During the experiment, no other auction where other vendor's could offer exactly the same product appeared on Allegro.pl.

The auctions conducted within each experiment were exposed in an automatic way, at exactly the same time, i.e. 0:00 in the night from Sunday to Monday.

The proposed scheme to start the auction guaranteed that parallel auctions popping up on the list of auction alternately (once auction "A" before "B", second time "B" before "A").

The presented structure does not refer to experiment No. 1. In the first experiment auction "A" always appears before auction "B" on the list of highlighted/featured auctions.

In each experiment the same number of goods was offered. For pouch E1 it was 20 units and for E2 - 10 units.

The designed structure of the experiments provided online auctions, in which the auction of all items being sold starts at the same time and ends at the same time.

Each auction was designed with an identical duration and they should have lasted seven days. In the study, a total of 24 auctions were started, two of which, unfortunately, ended before the end of a seven day period (one after 4 days, the other after 5 days), i.e. had already sold all of the offered pouches. To ensure the comparability of results for these two auctions, the parallel auctions were ended at the same time.

\section{Research hypotheses}

The total results presented in Table 2 allowed us to determine the direction of change, which in turn formed the basis for formulating the hypotheses. 


\section{Hypothesis 1.1 .}

If the auction has not been highlighted on the list of auctions, it has a negative impact on the number of hits on the website.

Hypothesis 1.2.

If the auction has not been featured on the list of auction, it has a negative impact on the sales volume.

Hypothesis 2.

The lower the auction sellers' reputation, the lower the online auction sales volume.

Hypothesis 3.

The less attractive form and product description, the lower the online auction sales volume. Hypothesis 4.1.

The higher price of the product and lower cost of delivery affect the number of hits on the website.

Hypothesis 4.2.

The higher price of the product and lower cost of delivery affect the online auction sales volume.

Hypothesis 5.1.

Amateur, made a mobile phone picture of the offered product has a positive effect on the number of hits on the website.

Hypothesis 5.2.

Amateur, made a mobile phone picture of the offered product has a positive effect on the online auction sales volume.

Hypothesis 6.1.

Auction title written in small letters instead of in capitals has a negative effect on the number of hits on the website.

Hypothesis 6.2.

Auction title written in small letters instead of in capitals has a negative effect on the online auction sales volume. 


\section{Findings}

As mentioned earlier, to determine the direction of change of the hypothetical observation the average values obtained in the particular experiments were used (Table 2).

Table 2. The total results for each experiment for E1 and E2

\begin{tabular}{|c|c|c|c|c|}
\hline \multirow{2}{*}{$\begin{array}{c}\text { No. of the } \\
\text { experiment }\end{array}$} & \multicolumn{2}{|c|}{$\begin{array}{c}\text { Average number } \\
\text { of hits per day } \\
\pm \text { standard deviation }\end{array}$} & \multicolumn{2}{c|}{$\begin{array}{c}\text { Average number } \\
\text { of items sold per day } \\
\pm \text { standard deviation }\end{array}$} \\
\cline { 2 - 5 } & auction A & auction B & auction A & auction B \\
\hline 1 & $59 \pm 23$ & $14 \pm 6$ & $1.9 \pm 1.6$ & $0.9 \pm 1.3$ \\
\hline 2 & - & - & $1.7 \pm 1.9$ & $0.5 \pm 0.7$ \\
\hline 3 & - & - & $1.2 \pm 1.5$ & $0.4 \pm 0.8$ \\
\hline 4 & $52 \pm 28$ & $24 \pm 15$ & $2.3 \pm 3.1$ & $0.1 \pm 0.3$ \\
\hline 5 & $38 \pm 19$ & $43 \pm 25$ & $1.2 \pm 2.5$ & $1.6 \pm 1.9$ \\
\hline 6 & $54 \pm 19$ & $25 \pm 12$ & $2.4 \pm 2.3$ & $1.4 \pm 1.9$ \\
\hline
\end{tabular}

Source: own research.

In order to test the presented research hypotheses, the data obtained from the experiments were analysed with the Wilcoxon Signed-Ranks test, a non-parametric statistical method used when comparing two related samples, matched samples, or repeated measurements on a single sample to assess whether their population mean ranks differ. The Wilcoxon Signed-Ranks test applies to two-sample designs involving repeated measures, matched pairs, or "before" and "after" measures.

Table 3. The research results - Wilcoxon Signed-Ranks test

\begin{tabular}{|c|c|c|c|}
\cline { 2 - 4 } \multicolumn{1}{c|}{} & $\mathrm{n}$ & $\mathrm{T}$ & Critical values \\
\hline H 1.1 & 14 & 0 & 26 \\
\hline H 1.2 & 7 & 4 & 4 \\
\hline H 2 & 8 & 3 & 6 \\
\hline H 3 & 8 & 7.5 & 6 \\
\hline H 4.1 & 11 & 3 & 14 \\
\hline H 4.2 & 8 & 0 & 6 \\
\hline H 5.1 & 14 & 42.5 & 26 \\
\hline H 5.2 & 10 & 19.5 & 11 \\
\hline H 6.1 & 11 & 0 & 14 \\
\hline H 6.2 & 7 & 2 & 4 \\
\hline
\end{tabular}

Source: own research. 
Seven of those research hypotheses are significant with the Wilcoxon Signed-Ranks test (H 1.1, 1.2, 2, 4.1, 4.2, 6.1, 6.2).

\section{Conclusions}

The results presented in table 3 clearly demonstrate that some of the tested signals strongly influence the online auction sales volume.

If the auction has not been highlighted on the list of the auction it has a negative impact on the number of hits on the website and on the sales volume.

Although the advantage of online auctions are relatively low the costs are entered for the e-seller, but without the additional capital investments (pay an additional fee to guarantee that the auction is highlighted/emphasized on the list) the effectiveness of the auction is low.

Arguments relating to seller reputations and their impact on online auctions have been repeatedly confirmed in studies. The auction seller reputation influences online sales volume.

The conducted experiment indicates that the lower seller reputation determines the lower auction sales volume.

Managerial implications should include e-retailers involvement in creating a positive image and credibility. The results indicate the possibility of creating an image of an auction platform (Allegro) based on arguments regarding the reliability of the e-sellers.

The analysis of the behaviour of auction customers' clearly indicates that they are price sensitive and conducting price comparisons with other offers. At the auction looking for goods at the best value (price vs. other arguments).

A buyer looking for goods on the Web usually has the choice of multiple listings for the same or a similar product. Usually the list of available auctions, is displayed on the screen, is long and gets acquainted with each bid takes a lot of time.

After reviewing several bids (auction), the customer may feel tired and fatigued.

If the purchase is not particularly important for the customer, we can assume that the buyer will not be particularly involved in reviewing the available listings. Probably from the auction list the buyer will choose a few. For the e-retailer, it is important that in such a case can be applied stimuli (signals) that already, at the level of the displayed list, will distinguished the auction from others and thereby increase the likelihood that the client will display and become familiarized with the content of the highlighted offer.

Due to the very large number of similar auctions it is necessary to distinguish the particular auction on the list. Without distinctive elements, the potential buyer just "misses" some action. 
Therefore an auction title written in small letters has a negative impact on the number of hits and on the sales volume. Additionally, capital letters are the only free of charge signal to highlight the auction according to Allegro.pl rules.

\section{Directions for future research}

The results suggest that several signals can be used to stimulate online customers' behaviour. However the conclusions should be implemented whereas the nature of the product used in the experiment (basic product, low customer involvement in the decision making process).

The results indicate that buyers are more susceptible to the influence of "visual" signals than signals that require greater involvement of the buyer (to read information).

To the growing interest in online auctions, it is important to identify signals that e-sellers use to induce shopping behaviour. Buyers will benefit from their inspection of signals offered by sellers. The presented results might be useful for regulatory institutions in their quest to educate online consumers and evaluate online markets.

We examine the role of website signals as a way for online retailers to stimulate online sales.

Future research can hypothesize on additional customer-level variables. It is possible that the signals have varying effects on different customer groups. For example, the factor differentiating effect (or the strength of the effect) on buyer behaviour can be buyer experience in online auctions (experienced vs. inexperienced bidders).

Also empirical tests can be conducted through controlled experiments for other products.

In the present study we used mobile phone pouches as a product which is the subject of the online auction. This product is of little significance for the buyer, and we can assume that, as such, does not cause a large commitment from the buyer in the purchasing process. It would be interesting to establish similar research for a product which has a greater importance purchase for the consumer (e.g. it is more expensive or has greater emotional significance), thus may change the meaning of the tested signals.

Such studies would be of particular interest to the opinion presented above that the online buyer does not pay much attention to the design of the product description. Based on the overall experience, we could hypothesize that the attitude of buyers in this situation will be different, depending on the importance of the product to the buyer. 


\section{Acknowledgements}

The authors wish to thank Mr Jakub Kopacki for assistance in conducting the experiment and valuable support in the implementation of the research.

\section{References}

Akerlof, G. (1970). The Market for Lemons: Quality Under Uncertainty and the Market Mechanism, Quarterly Journal of Economics, 84 (3): 488-500.

Asch, S.E. (1956). Studies of independence and conformity: a majority of one against a unanimous majority. Psychological Monographs (pp. 70-79).

Biswas, D. \& Biswas, A. (2004). The Diagnostic Role of Signals in the Context of Perceived Risk in online Shopping: Do Signals Matter More on the Web? Journal of Interactive Marketing, 18 (3): 30-45.

Bo, X., Zhangxi, L. \& Bingjia S. (2010). Factors affecting consumer behaviors in online buy-itnow auctions. Internet Research, 20 (5): 509-526.

Bonabeau, E. (2004). The perils of the imitation age. Harvard Business Review, 82: 99-104.

Chen, Y-F. (2008). Herd behavior in purchasing books online. Computers in Human Behavior, 24: 1977-92.

Chen, Y-F. \& Wang, Y-J. (2010). Effect of Herd Cues and Product Involvement on Bidder Online Choices. Cyberpsychology, Behavior and Social Networking, 14 (7-8): 411-416.

Chen, Y-F. (2011). Auction Fever: Exploring Informational Social Influences on Bidder Choices. Cyberpsychology, Behavior and Social Networking, 13 (4): 423-428.

Dawar, N. \& Parker, P. (1994). Marketing Universals: Consumers' Use of Brand Name, Price, Physical Appearance, and Retailer Reputation as Signals of Product Quality. Journal of Marketing, 58 (2): 81-95.

Donath, J. (2007). Signals in Social Supernets. Journal of Computer-Mediated Communication, 13, (1): 231-251.

Erdem, T. \& Swait, J. (1998). Brand Equity as a Signaling Phenomenon. Journal of Consumer Psychology, 7 (2): 131-157.

Gregg, D. \& Scott, J. (2006). The Role of Reputation Systems in Reducing Online Auction Freud. International Journal of Electronic Commerce, 10 (3): 97-122.

Gregg, D. \& Walczak, S. (2008). Dressing Your Online Auction Business For Success: An Experiment Comparing Two eBay Businesses. MIS Quarterly, 32 (3): 653-670. 
Hanson, W.A. \& Putler, D.S. (1996). Hits and misses: herd behavior and online product popularity. Marketing Letters, 7: 297-305.

Hasson, O. (2000). Knowlegde, information, biases and signal assemblages. In: Animal Signals. Signalling and Signal Design in Animal Communication. Eds. Y. Espmark, T. Amundsen, G. Rosenqvist. The Royal Norwegian Society of Sciences and Letters, The Foundation of Tapir Publishers, Trondheim, Norway (pp. 445-463).

InternetStandard Report (2013). www.ecommercestandard.pl.

Kim, D., Ferrin, D. \& Rao, H. (2008). A trust-based consumer decision-making model in electronic commerce: The role of trust, perceived risk, and their antecedents. Decision Support System, 22 (2): 544-564.

Lascu, D.-N. \& Zinkhan, G. (1999). Consumer conformity: review and applications for marketing theory and practice. Journal of Marketing Theory \& Practice, 7: 1-12.

Lee, J., Park, D.H. \& Han, I. (2008). The effect of negative online consumer reviews on product attitude: an information processing view. Electronic Commerce Research \& Applications, 7: $341-52$.

Lo, S.-K., Chiu, Y.-P. \& Hsieh, A.-Y. (2013). Photograph and model use within an online auction page for influencing buyer's bidding behavior. Online Information Review, 37 (3): 354-368.

Mavlanova, T., Benbunan-Fich, R. \& Koufaris, M. (2012). Signaling theory and information asymmetry in online commerce. Information \& Management, 49 (5): 240-247.

Maynard-Smith, J. \& Harper, D. (2004). Animal Signals. Oxford Series in Ecology and Evolution.

Min-Young, L., Youn-Kyung, K. \& Hyun-Joo, L. (2013). Adventure versus gratification: emotional shopping in online auctions. European Journal of Marketing, 47 (1/2): 49-70.

Mitra, D. \& Fay, S. (2012). Managing Service Expectations in Online Markets: A Signaling Theory in E-tailer Pricing and Empirical Test. Journal of Retailing, 86 (2): 184-199.

Miyazaki, A.D., Greval, D. \& Goodstein, R.C. (2005). The Effect of Multiple Extrinsic Cues on Quality Perceptions: A Matter of Consistency. Journal of Consumer Research, 32 (1): $146-153$.

Nanarpuzha, R. (2014). Marketing semiotics: Signs, strategies, and brand value. European Journal of Marketing, 48 (5/6).

Oswald, L.R. (2012). Marketing Semiotics: Signs, Strategies, and Brand Value. Oxford University Press.

Purohit, D. \& Srivastava, J. (2001). Effect of Manufacturer Reputation, Retailer Reputation, and Product Warranty on Consumer Judgments of Product Quality: A Cue Diagnosticity Framework. Journal of Consumer Psychology, 10 (3): 123-134. 
Rao, A.R. (2005). The Quality of Price as a Quality Cue. Journal of Marketing Research, 42 (4): 401-405.

Rao, A.R. \& Monroe, K.B. (1989). The Effect of Price, Brand Name, and Store Name on Buyers' Perceptions of Product Quality: An Integrative Review. Journal of Marketing Research, 26 (3): 351-357.

Resnick, P. \& Zeckhauser R. (2002). Trust Among Strangers in Internet Transactions: Empirical Analysis of eBay's Reputation System. In: The Economics of The Internet and E-Commerce. Ed. M.R. Baye, Vol. 11 of Advanced in Applied Microeconomics. Amsterdam, JAI Press (pp. 127-157).

Resnick, P., Zeckhauser R., Swanson, J. \& Lockwood, K. (2006). The value of reputation on eBay: A controlled experiment. Experimental Economics, 9 (2): 79-101.

Richardson, P.S., Dick A.S. \& Jain, A.K. (1994). Extrinsic and Intrinsic Cue Effects on Perceptions of Store Brand Quality. Journal of Marketing, 58(4): 28-36.

San Martin, S. \& Camarero, C. (2009). How perceived risk affects online buying. Online Information Rewiev, 33 (4): 629-654.

Shen, C.-C., Chiou, J.-S. \& Kuo, B.-S. (2011). Remedies for information asymmetry in online transaction. An investigation into the impact of web page signals on auction outcome. Internet Research, 21 (2): 154-170.

Spence, M. (1974). Market-Signaling, Cambridge MA, Harvard University Press.

Wanat, T. \& Grzesiuk, A. (2009). The influence of the number of opinions on the attractiveness of retailers offer in online shopping. Proceedings of International Conference on E-Business, Milan, Italy.

Wu, W.-Y., Huang, P.C. \& Fu, C.-S. (2011). The influence of an online auction's product price and e-retailer reputation on consumer's perception, attitude and behavioral intention. Scandinavian Journal of Psychology, 52: 590-302. 